This article is part of a Research Dialogue:

Gelman \& Echelbarger (2019): https:/ /doi.org/10.1002/jcpy.1097

John \& Chaplin (2019): https://doi.org/10.1002/jcpy.1094

Oyserman (2019): https:/ /doi.org/10.1002/jcpy.1093

Gelman \& Echelbarger (2019): https:/ / doi.org/10.1002/jcpy.1096

\title{
Introduction to the Research Dialogue on Children and Persuasion
}

\author{
Aradhna Krishna \\ University of Michigan
}

Keywords Children; Persuasion; Perception; Judgment; Intervention

\section{Introduction}

If a piece of clay belonging to one person transferred hands, when would 3-year olds judge that it belonged to the second person? Would they care if there was some creative labor applied to the clay in making their judgment or would that logic be too subtle for 3-year olds? Likewise, when would 4-year olds think that paint on a canvas was a painting? Would they care if paint was intentionally applied or if it was spilled by accident? The answers to these questions address the development of subtle judgment in children. As it stands, in the field of consumer psychology, little work has been done with children. Consumer psychology research has mostly been focused on young adults, opportunistically using student subjects at universities. This research dialogue brings attention to the importance and sheer beauty of doing research with children. Gelman is one of our foremost development psychologists, with research examining essentialism (Gelman, 2003), preference for objects (Gelman \& Davidson, 2016), monetary evaluation (Gelman, Frazier, Noles, Manczak, \& Stilwell, 2015), understanding of ownership (Gelman, Manczak, \& Noles, 2012), digital privacy perceptions among children (Gelman, Martinez, Davidson, \& Noles, 2018), and a host of other areas. John arguably has the largest body of consumer behavior research involving children (see, e.g., John, 1981, 1999), and Oyserman has been doing interventions in public schools around the world to increase children's

Correspondence concerning this article should be addressed to Aradhna Krishna, Dwight F. Benton of Marketing, University of Michigan, Ann Arbor, MI, USA. Electronic mail may be sent to aradhna@umich.edu. engagement in school work (see Nurra \& Oyserman, 2018). These three prominent researchers along with their co-authors, Echelbarger and Chaplin, offer different, but synergistic perspectives on children and persuasion.

Gelman and Echelbarger's (GE) target article points out a presumption made by many developmental psychologists that children's reasoning relies on surface features and that children are unable to grasp abstractions (e.g., Rakison \& Oakes, 2003). In their article, GE provide a large body of evidence which shows the opposite - that even at a very young age ( 3 years old), children can make subtle judgments. GE review research (much of their own, and also of other authors) which shows when, how, and why children may be affected by nonvisible features of objects (animals, foods, artifacts, ideas). For the selection of nonvisible features, they focus on two conceptual orientations - essentialism (an underlying nonobvious reality or inner quality shared by all members of a natural category) and object history (an acquired feature distinctive to an individual). Using a multitude of clever studies, they show that essence and object history can impact the psychological and monetary value of objects for children. The studies include those addressing the two questions raised at the beginning-3-year olds transfer ownership of the clay only when creative labor has been expended by the second person; 4-year olds conceive of paint on a canvas as a painting only when it is intentional.

(C) 2019 Society for Consumer Psychology

All rights reserved. 1057-7408/2019/1532-7663/29(2)/306-308 DOI: $10.1002 /$ jcpy.1095 
The two commentaries which follow the target article are both focused on persuasion-how object value can be changed by external forces. Note that the commentaries too offer perspectives that are relatively novel to consumer behavior-they offer new perspectives on persuasion. While most persuasion research in consumer behavior uses theories of dual-processing (Chaiken \& Eagly, 1976; Petty \& Cacioppo, 1986), or reasoned-action (Fishbein \& Ajzen, 2011), the commentaries focus more on social influence (John and Chaplin) and on identity and culture (Oyserman). The commentaries try to link the target article's discussion on children's concepts of object value to broad issues involving persuasion, in the forms of choices, behaviors, and values.

While GE do not consider brand as part of the object value, John and Chaplin's commentary examines how children value products and brands as a basis for meeting the goals of identity formation, self-presentation and happiness. In doing this, they highlight that products and brands can imply status, prestige, and social meaning; and that brands and products are used for these goals more readily as children get older. John and Chaplin develop the use of collages for their experiments with children, where children can, for instance, make collages to represent who they are. These collages then allow the researchers to see the number of products and brands that are part of the children's self-concept ("who am I?"). Their data analysis also looks at how reasons for including brands vary across children's ages - for instance, Old Navy may be part of an 8-year old's self-concept because she wears a lot of Old Navy clothes, but a 17-year old may put a brand on her self-concept collage because of similarities in her personality and the brand's, revealing much more sophisticated thinking.

Taking a different perspective on persuasion, Oyserman argues very convincingly that persuasion attempts are more likely to be successful if they are congruent with the ways in which people think of themselves and their surroundings. Just like GE argue that object value can be based on the object "essence" perceived by children, Oyserman argues that children themselves have essentialized selves linked to identity and culture - and if the persuasion attempt matches this essentialized self, it will have better compliance with the persuasion attempt. She presents various interventions with children (and adults) to provide evidence of this. In a powerful intervention, Nurra and Oyserman (2018) randomly assigned fourth to sixth graders to two groups - one group was told that being an adult is near to the present because it arrives soon. Another group was told that being an adult is far from present because it arrives in a long time. The former group was found to be much more engaged in schoolwork. Actual such interventions in schools (using twelve 30-min identity-based motivation activities over 6 weeks of the school year) have shown an increase in attendance and school grades, and are now being sought by schools around the world. Oyserman also brings out conceptual differences in how she thinks of essentialism versus GE.

Gelman and Echelbarger's rejoinder to the two commentaries brings up three areas related to exploring the links among objects, motivation, and the self. First, when (i.e., at what age) and why (i.e., based on what aspect of societal structure) do links among object concepts, motivation, and the self-concept develop? Here, GE also urge future researchers to try and separate universal and culturally specific influences on children. Second, how can different motivational consequences of essentialism be reconciled? Per Oyserman, goals should be linked to one's essentialized identity in order to be motivating and to be pursued; however, making an individual trait essential (viewing it as fixed and determined by nature) can be demotivating if one has faced a failure or setback (e.g., Dweck \& Bempechat, 1983). Third, what is the role of psychological ownership on sustainability? GE focuses primarily on tangible objects; but feelings of ownership can extend beyond objects to include sustainable natural resources, such as parks and forests. They end the rejoinder by pointing out the importance of studying children within the field of consumer psychology since expectations and preferences may be formed in childhood, and subsist for a long time. Contrarily, one cannot draw conclusions about children by studying adult behavior, since children may behave very differently compared to adults.

Beyond the areas suggested by the dialogue authors, I would also like to suggest three other potential areas of research concerning childrenqualitative research on what marketers are doing to persuade children (see e.g., recent work by Tian, Nelson, Ahn, \& Ferguson, 2018, where they monitor food and beverage references within $64.5 \mathrm{hr}$ of children's television programs), research with pre-verbal children-are they also persuaded by marketers (see, e.g., Buvinger, Rosenblum, Miller, Kaciroti, \& Lumeng, 2017); and epigenetic research to see what inherent proclivities may reside in children affecting their preference formation and 
persuasion. As one can see, much research is needed on children and persuasion, and much more on other perceptions and behaviors of children related to consumption. This dialogue should help in that direction.

\section{References}

Buvinger, E., Rosenblum, K., Miller, A. L., Kaciroti, N. A., \& Lumeng, J. C. (2017). Observed infant food cue responsivity: Associations with maternal report of infant eating behavior, breastfeeding, and infant weight gain. Appetite, 112, 219-226. https://doi.org/10.1016/j. appet.2017.02.002

Chaiken, S., \& Eagly, A. H. (1976). Communication modality as a determinant of message persuasiveness and message comprehension. Journal of Personality and Social Psychology, 34, 605-614. https://doi.org/10.1037/ 0022-3514.34.4.605

Dweck, C. S., \& Bempechat, J. (1983). Children's theories of intelligence: Consequences for learning. In S. Paris, G. Olson, \& H. Stevenson (Eds.), Learning and motivation in the classroom (pp. 239-256). Hillsdale, NJ: Erlbaum.

Fishbein, M., \& Ajzen, I. (2011). Predicting and changing behavior: The reasoned action approach. New York, NY: Psychology Press.

Gelman, S. A. (2003). The essential child: Origins of essentialism in everyday thought. New York: Oxford University Press. https://doi.org/10.1093/acprof:oso/ 9780195154061.001.0001

Gelman, S. A., \& Davidson, N. S. (2016). Young children's preference for unique owned objects. Cognition, 155, 146154. https:/ / doi.org/10.1016/j.cognition.2016.06.016

Gelman, S. A., Frazier, B. N., Noles, N. S., Manczak, E. M., \& Stilwell, S. M. (2015). How much are Harry
Potter's glasses worth? Children's monetary evaluation of authentic objects. Journal of Cognition and Development, 16, 97-117. https://doi.org/10.1080/15248372. 2013.815623

Gelman, S. A., Manczak, E. M., \& Noles, N. S. (2012). The nonobvious basis of ownership: Preschool children trace the history and value of owned objects. Child Development, 83, 1732-1747. https://doi.org/10.1111/j. 1467-8624.2012.01806.x

Gelman, S. A., Martinez, M., Davidson, N. S., \& Noles, N. S. (2018). Developing digital privacy: Children's moral judgments concerning mobile GPS devices. Child Development, 89, 17-26. https://doi.org/10.1111/cdev. 12826

John, D. R. (1981). Age differences in children's responses to television advertising: An information-processing approach. Journal of Consumer Research, 8, 144-153.

John, D. R. (1999). Consumer socialization of children: A retrospective look at twenty-five years of research. Journal of Consumer Research, 26, 183-213. https://doi.org/ $10.1086 / 209559$

Nurra, C., \& Oyserman, D. (2018). From future self to current action: An identity-based motivation perspective. Self and Identity, 17, 343-364. https://doi.org/10. 1080/15298868.2017.1375003

Petty, R. E., \& Cacioppo, J. T. (Eds) (1986). The elaboration likelihood model of persuasion. In Communication and persuasion (pp. 1-24). New York: Springer. https: / / doi.org/10.1007/978-1-4612-4964-1

Rakison, D. H., \& Oakes, L. M. (Eds.) (2003). Early category and concept development: Making sense of the blooming, buzzing confusion. New York: Oxford University Press.

Tian, K., Nelson, M., Ahn, R., \& Ferguson, G. (2018). Krabby patties, kelp chips, or KitKats?: Exploring the depictions of food featured in children's television shows. Poster presented at ACR conference, Dallas. 